\title{
Potensi Ekowisata di Bukit Cinta Danau Rawapening Kabupaten Semarang
}

\author{
Nurul Lathifah ${ }^{1}$, Jafron Wasiq Hidayat², dan Fuad Muhammad ${ }^{2}$ \\ ${ }^{1}$ Magister Biologi Universitas Diponegoro; e-mail: nurullathifahl@gmail.com \\ 2 Fakultas Sains Dan Matematika Universitas Diponegoro
}

\begin{abstract}
ABSTRAK
Indonesia mempunyai berbagai jenis sumberdaya hayati potensial yang dapat dimanfaatkan sebagai objek daya tarik wisata unggul, salah satunya adalah Bukit Cinta Danau Rawapening. Objek wisata tersebut menyajikan landskap alami dan berlokasi di pertemuan Semarang-Solo-Yogyakarta. Potensi sumberdaya dan lokasi yang strategis membuat objek wisata tersebut menjadi salah satu dari 15 danau prioritas nasional, namun demikian masih banyak potensi sumberdaya hayati yang dapat diikembangkan untuk membangun ekowisata di Bukit Cinta Danau Rawapening. Tujuan dari penelitian ini untuk mengidentifikasi sumberdaya biotik terhadap ekowisata dan mengkaji potensi ekowisata di Bukit Cinta Danau Rawapening Kabupaten Semarang. Penelitian ini dilakukan pada bulan September 2018-Maret 2019 dengan mengumpulkan data primer yang meliputi keanekaragaman plankton, makrobenthos, nekton, vegetasi, fisika kimia perairan, potensi objek wisata, dan data sekunder meliputi keanekaragaman burung, jumlah pengunjung. Parameter biotik dianalisis strukturnya sedangkan kualitas air status fisik-kimia. Penilaian potensi daerah wisata menggunakan metode ADO-ODTWA Danau. Berdasarkan hasil penelitian di Bukit Cinta Danau Rawapening dalam aspek biotik memperlihatkan bahwa biota yang mendominasi adalah Melosira sp, Tarebia granifera, Oreochromis niloticus, Eichhornia crassipes, Bubulcus ibis, dan kualitas air masih layak digunakan sebagai tempat wisata. Berdasarkan hasil penilaian identifikasi potensi daerah wisata Bukit Cinta Danau Rawapening termasuk dalam klasifikasi tinggi dengan nilai 6310. Hal ini mengindikasikan bahwa objek wisata Bukit Cinta Danau Rawapening memiliki potensi yang layak untuk dikembangkan menjadi destinasi ekowisata.
\end{abstract}

Kata kunci: Ekowisata, Sumberdaya hayati, Bukit Cinta, Danau Rawapening, ADO-ODTWA

\begin{abstract}
Indonesia have several varieties of potential biological sources that beneficial for a superior tourist attraction one of of them is Bukit Cinta Lake Rawapening. The attraction presents a natural landscape which is located at the Semarang-Solo-Yogyakarta meeting. The potential resources and strategic location make this tourist attraction become one of the 15 national priority lakes, however there is still plenty of biodiversity that can be developed to build ecotourism at Bukit Cinta Rawapening Lake. The study purpose was to identify biotic resources for ecotourism and to study ecotourism potential in the Lake of Love Lake Rawapening Regency of Semarang. The purpose of this study to identify the biotic resources to the ecotourist at fraction Rawapening Lake and is also to examines the potential of ecotourism in Bukit Cinta Lake Rawapening Semarang Regency. This research was conducted in September 2018-March 2019 by collecting primary data covering the diversity of plankton, macrobenthos, nekton, vegetation, chemical physics of waters, the potential of tourist attractions, and secondary data including bird diversity, number of visitors. Biotic parameters are analyzed its structure whilst the physical-chemical status water quality. Assessment of potential tourist areas using the ADO-ODTWA Lake methode. Based on this study, Bukit Cinta Lake Rawapening, in the biotic aspect shows that the dominating biota are Melosira sp, Tarebia granifera, Oreochromis niloticus, Eichhornia crassipes, Bubulcus ibis, and water quality is still suitable for use as tourist attractions. Based on the results of the assessment of the potential of Bukit Cinta tourism area, Lake Rawapening is included in the high classification with a value of 6310. This indicates that the Bukit Cinta Lake Rawapening tourist attraction have potential on the ecotourism destination potential.
\end{abstract}

Keywords: Ecotourism, Biological resources, Bukit Cinta, Lake Rawapening, ADO-ODTWA

Citation: Lathifah, N., Hidayat, J. W. dan Muhammad, F. (2020). Potensi Ekowisata di Bukit Cinta Danau Rawapening Kabupaten Semarang, 18(2), 228-235, doi:10.14710/jil.18.2.228-235

\section{Pendahuluan}

Indonesia mempunyai berbagai jenis sumberdaya hayati potensial yang dapat dimanfaatkan sebagai objek daya tarik wisata unggul, salah satunya adalah Bukit Cinta Danau
Rawapening, Kabupaten Semarang. Danau yang termasuk dalam 15 danau prioritas nasional tersebut menyajikan landskap atau bentang pemandangan yang alami. Bukit Cinta Danau Rawapening dikelilingi 4 pegunungan jika dilihat 
dari bentang alamnya, yaitu Gunung Telomoyo, Gunung Merbabu, Gunung Kendali Sodo, dan Gunung Ungaran; dan terletak di tengah triangle YogyakartaSemarang-Solo yang sangat strategis sehingga berpotensi untuk dikembangkan menjadi objek ekowisata.

Kawasan ekowisata merupakan kawasan yang memiliki pemandangan alami yang khas, meliputi unsur biotik abiotik seperti flora dan fauna endemik, keadaan iklim, dan tatanan sosial budaya. Hal tersebut merupakan potensi objek ekowisata untuk dapat dimanfaatkan dan dikembangkan secara optimal (Damanik dan Helmut, 2007). Status biologis, eutrofikasi dan tinggi rendahnya kapasitas danau memicu adanya tindakan perlindungan terhadap Danau Rawapening sehingga dapat dikembangan menjadi kawasan ekowisata. Kawasan tersebut dapat berpotensi untuk meningkatkan perekonomian berbasis konservasi sehingga bermanfaat dan dapat diterima dengan baik oleh masyarakat, Strategi ekowisata dapat terus dikembangkan untuk meminimalisir terjadinya degradasi kawasan dimasa mendatang (Tiga dkk, 2019).

Status objek wisata Bukit Cinta Danau Rawapening adalah wisata alam yang telah diperkaya dengan beragam atraksi, seperti berperahu, duduk santai dan memancing. Penelitian terdahulu terkait sejarah kawasan, keadaan ekonomi dan pemanfaatan sektor pertanian dan perikanan pariwisata telah dilakukan (Mochtar, 2004), namun studi terkait potensi ekowisata berbasis konservasi sumberdaya alam hayati, terutama di sektor biotik di kawasan tersebut belum pernah dilakukan. Aryanto dkk (2016) menyatakan bahwa sumberdaya alam hayati banyak disukai dan berpotensi mendukung ekonomi serta edukasi masyarakat dengan pengelolaan secara selaras, disamping adanya pengkayaan atraksi.

Oleh karena itu, perlu adanya penelitian yang mengidentifikasi dan mengkaji sumberdaya biotik sebagai potensi ekowisata di Bukit Cinta Danau Rawapening Kabupaten Semarang. Penelitian ini diharapkan dapat menjadi solusi alternatif dalam mendukung pengembangan ekowisata di Bukit Cinta Danau Rawapening.

\section{Gambar dan Tabel}

Penelitian dilaksanakan pada bulan September 2018-Maret 2019 di Bukit Cinta Danau Rawapening, Kabupaten Semarang. Studi ini menggunakan alat dan bahan berupa plankton net ukuran 25, Ekman grab, Electrofishing, jaring, alat tulis, kamera digital, pH meter, water cheker, DO meter, alkohol, formalin $10 \%$, dan aquades dan lembar questioner. Penelitian dilakukan dengan mengumpulkan data primer dan sekunder. Data primer yang diambil meliputi keanekaragaman plankton, makrobenthos, nekton, vegetasi, fisika kimia perairan, dan potensi objek wisata, sedangkan data sekunder meliputi keanekaragaman burung dan jumlah pengunjung. Sampling dilakukan dengan mengamati objek secara langsung, sedangkan pengumpulan data sekunder dikumpulkan melalui informasi Dinas Pariwisata Kabupaten Semarang. Data penelitian ini dikelompokkan menjadi beberapa aspek antara lain: biotik (keanekaragaman plankton, makrobenthos, nekton, burung, dan vegetasi), abiotik (suhu, bau, warna, pH, DO), dan aspek sosial ekonomi (masyarakat lokal, pengunjung, pemerintah daerah, dan stakeholder).

Data keanekaragaman plankton dihitung berdasarkan rumus APHA (2005) sebagaimana dilakukan Lathifah dkk (2017). Keanekaragaman plankton dianalisis menggunakan indeks kemerataan dan indeks keanekaragaman ShannonWiener, yang dianalisis menggunakan rumus di bawah ini.

$$
N=\frac{T}{L} \times \frac{p 1}{p 2} \times \frac{V 1}{V 2} \times \frac{1}{W}
$$

$N$ menunjukkan nilai kelimpahan plankton (ind/L); $T$ menunjukkan jumlah kotak dalam SRC (1000); $L$ menunjukkan jumlah kotak dalam satu lapang pandang; $P 1$ menunjukkan jumlah plankton yang teramati, $P 2$ menunjukkan jumlah kotak SRC yang diamati, $V 1$ menunjukkan volume air dalam botol sampel, $V 2$ menunjukkan volume air dalam kotak SRC dan $W$ menunjukkan volume air yang tersaring.

Keanekaragaman plankton dianalisis berdasarkan rumus Shannon Wiener (Magurran, 1988):

$$
H^{\prime}=-\sum_{i=1}^{n} p i \ln p i \text { dengan } p i=\frac{n i}{N}
$$

$H^{\prime}$ adalah indeks Keanekaragaman ShannonWiener; $n i$ adalah jumlah jenis ke-I; dan $N$ adalah jumlah total jenis.

Kemerataan plankton dianalisis dengan rumus:

$$
\boldsymbol{e}=\frac{\boldsymbol{H}^{\prime}}{\boldsymbol{H}_{\text {maks }}}
$$

$e$ merupakan Indeks kemerataan Genus; $H^{\prime}$ merupakan Indeks Keanekaragaman Genus; dan $H_{\text {maks }}$ merupakan Indeks Keanekaragaman Maksimum.

Kualitas lingkungan perairan dari kehidupan plankton dianalisis menggunakan koefisien saprobik yang direpresentasikan melalui persamaan Dresscher and Van Der Mark (1974), dengan rumus:

$$
X=\frac{C+3 D-B-3 A}{A+B+C+D}
$$

$X$ adalah Koefisien Saprobik; $A$ merupakan Jumlah Spesies Kelompok Cyanophyta (Polisaprobik); $B$ adalah Jumlah Spesies Kelompok Euglenophyta $(\alpha-$ Mesosaprobik); $C$ adalah Jumlah Spesies Kelompok Chlorophyta ( $\beta$-Mesosaprobik); dan $D$ adalah Jumlah Spesies Kelompok Crhysophyta (Oligosaprobik). 
Tabel 1. Indeks Saprobitas melalui Penafsiran Kualitas Air secara Biologis.

\begin{tabular}{|c|c|c|c|}
\hline $\begin{array}{c}\text { Beban } \\
\text { Pencemaran }\end{array}$ & $\begin{array}{c}\text { Derajat } \\
\text { Pencemaran } \\
\end{array}$ & Fase Saprobik & $\begin{array}{c}\text { Indeks } \\
\text { Saprobik } \\
\end{array}$ \\
\hline \multirow[t]{2}{*}{ Banyak Senyawa Organik } & Sangat & Polisprobik & -3 hingga -2 \\
\hline & Tinggi & Poli/ $\alpha$-Mesosaprobik & -2 hingga $-1,5$ \\
\hline Senyawa Organik dan & Agak & $\alpha$-Meso/Polisaprobik & $-1,5$ hingga -1 \\
\hline \multirow[t]{2}{*}{ Anorganik } & Tinggi & $\alpha$-Mesosaprobik & -1 hingga $-0,5$ \\
\hline & Sedang & $\alpha / \beta$-Mesosaprobik & $-0,5$ hingga 0 \\
\hline Sedikit & & $\beta / \alpha$-Mesosaprobik & 0 hingga $+0,5$ \\
\hline Senyawa & Ringan/ & $\beta$-Mesosaprobik & $+0,5$ hingga +1 \\
\hline Organik dan & Rendah & $\beta$-Meso/ Oligosaprobik & +1 hingga $+1,5$ \\
\hline \multirow[t]{2}{*}{ Anorganik } & Sangat & Oligo/ $\beta$-Mesosaprobik & $+1,5$ hingga +2 \\
\hline & Ringan & Oligosaprobik & +2 hingga +3 \\
\hline
\end{tabular}

Sumber: Pantle and Buck (1955) dalam Lathifah (2017).

Data keanekaragaman makrobenthos dilakukan menggunakan Ekman Grab ukuran 240. Komposisi individu makrobenthos menggambarkan jenis yang terdapat di lingkungannya (Pawhestri dkk, 2015). Kelimpahan jenis dianalisis berdasarkan jumlah individu per satuan volume (ind $/ \mathrm{m}^{3}$ ) (Taqwa, 2014).

$$
\mathrm{X}=\frac{\sum_{i=1}^{n} X i}{n}
$$

$\mathrm{X}$ merupakan rata-rata jumlah individu pada pengambilan contoh sebanyak n kali; Xi merupakan jumlah individu pada pengambilan contoh ke-I dan $\mathrm{N}$ merupakan Jumlah pengambilan contoh.

Data keanekaragaman nekton dilakukan dengan sampling menggunakan electrofishing (Machnaughton, 2015) dan wawancara dengan nelayan. Kepadatan populasi nekton dianalisis melalui perhitungan jumlah individu per $\mathrm{m}^{3}$, menggunakan rumus Azmi dkk (2015) sebagai berikut:

$$
\mathbf{K}=\frac{a i}{b}
$$

K merupakan Kepadatan Populasi (ind $/ \mathrm{m}^{3}$ ); ai merupakan Jumlah individu suatu spesies (ind); dan b merupakan Luas area $\left(\mathrm{m}^{2}\right)$.

Data keanekaragaman burung diproses menggunakan data sekunder berbasis metode line transect (Khalida, 2015) yang telah dimodifikasi, dianalisis secara deskriptif. Struktur komunitas dihitung menggunakan indeks kemerataan (e) dan keanekaragaman Shannon-Wiener $(\mathrm{H})$. Data vegetasi dianalisis deskriptif dengan survey lapangan.

Penilaian mengenai kelayakan terhadap objek daya tarik wisata dianalisis menggunakan kriteria penilaian berdasarkan Pedoman Penilaian Daya Tarik Wisata (ADO-ODTWA, 2003). Sebanyak 15 kriteria penilaian digunakan dalam penetuan ADOODTWA, dimana 5 kriteria utamanya adalah aksesibilitas, akomodasi, daya tarik, kondisi sosial ekonomi dan sarana pengunjung.

Aspek abiotik (bau, suhu, warna, pH dan DO) dianalisis menggunakan analisis deskriptif berdasarkan parameter fisika dan kimia yang sesuai dengan standar baku mutu kualitas air. Aspek sosial ekonomi yang meliputi presepsi masyarakat lokal, pengunjung, pemerintah daerah dan stakeholder dianalisis menggunakan metode SWOT. Persepsi masyarakat lokal, pengunjung dan stake holder diperoleh dengan kuesioner, masing-masing 40 orang untuk masyarakat lokal dan pengunjung serta 5 orang untuk stake holder sesuai dengan rumus slovin (Sugiyono, 2011). Penilaian objek daya tarik wisata mengacu pada Departemen Kehutanan Ditjen PHKA (2003) dan kriteria sebagaimana pedoman ADO-ODTWA.

\section{Hasil dan Pembahasan}

Danau Rawapening secara administratif berada di Kabupaten Semarang dan terletak di 4 kecamatan yaitu Bawen, Ambarawa, Bnyubiru, dan Tuntang. Letak geografis danau tersebut adalah 7004'-7030'LS dan $110^{0} 44^{\prime}$ BT dengan ketinggian 460 meter diatas permukaan laut. Danau Rawapening memiliki luas area 25.079 ha dengan sub Daerah Aliran Sungai (DAS) bersumber dari 9 sungai, yaitu Kedungringin, Sraten, Muncul, Legi, Galeh, Torong, Panjang, Ngaglik, dan Parat, serta 4 mata air, yaitu Petit, Dadang, Pening, dan Muncul. Analisis potensi ekowisata Bukit Cinta Danau Rawapening berbasis konservasi sumberdaya alam hayati, terutama di sektor biotik secara terperinci sangat penting untuk dipelajari sehingga dapat menjadi acuan dalam pengembangan ekowisata di tempat tersebut. Sumberdaya hayati tersebut diantaranya plankton, makrobenthos, nekton, burung, dan vegetasi yang akan dibahas selanjutnya.

Plankton adalah organisme mikroskopik air yang mempunyai kemampuan gerak terbatas mempunyai peran sentral dalam rantai makanan ekosistem perairan, baik sebagai produsen maupun konsumen primer (Champalbert dkk, 2007). Distribusi plankton dapat dijadikan sebagai penentu kesuburan perairan karena merupakan sumber pakan bagi organisme perairan. Berdasarkan pengamatan yang telah dilakukan, terdapat 12 jenis plankton tang berada di Danau Rawapening Kabupaten Semarang yaitu 11 jenis fitoplankton dan 1 jenis zooplankton meliputi Cyclops sp. Sebanyak 11 jenis fitoplankton yang ditemukan terdiri dari 3 divisio, antara lain Bacillariophyta sebanyak 5 jenis (Aulacoseira sp, Melosira sp, Navicula sp, Nitzchia sp, Synedra sp), Chlorophyta 2 jenis (Chlorella sp, Scenedesmus sp), dan Cyanophyta sebanyak 4 jenis (Anabaena sp, Oscillatoria sp, Peridinium sp, Spirulina sp). Jumlah individu yang paling banyak ditemukan adalah Melosira sp (357 individu/liter). Melosira sp banyak ditemukan di perairan Danau 
Rawapening karena Melosira sp memiliki kemampuan beradaptasi dengan perubahan lingkungan, seperti perubahan fisika dan kimia perairan (Piranti dkk, 2018). Data tersebut menunjukkan populasi fitoplankton yang lebih banyak dari zooplankton. Hal ini disebabkan perbedaan laju pertumbuhan kedua mikroorganisme tersebut, dimana lebih panjangnya siklus reproduksi zooplankton membuat populasinya lebih sedikit dari fitoplankton (Odum, 1996).

Berdasarkan hasil penelitian, diperoleh indeks keanekaragaman, kemerataan dan nilai koefisien saprobik plankton dengan nilai masing-masing 1.97, 0.79 dan 0.45. Hasil tersebut menunjukkan bahwa tingkat keanekaragaman plankton di kawasan Danau Rawapening tergolong sedang dengan tingkat kemerataan yang tinggi. Keanekaragaman plankton di suatu kawasan danau dapat menggambarkan tingkat pencemaran perairan di danau tersebut (Effendi, 2003). Tingkat keanekaragaman plankton yang tergolong sedang di Danau Rawapening menunjukkan tingkat pencemaran yang rendah. Hal ini juga didukung dengan nilai koefisien saprobik yang menunjukkan bahwa perairan tersebut berada dalam fase $\beta / \alpha$-Mesosaprobik dengan tingkat pencemaran ringan sehingga kualitas air masih layak digunakan sebagai tempat wisata (Mochtar, 2004). Tingkat kemerataan plankton yang tinggi juga menunjukkan persebaran plankton yang merata, tidak adanya spesies yang mendominasi dan peluang hidup spesies yang merata. Hal tersebut menunjukkan ekosistem perairan Danau Rawa pening yang seimbang (Piranti dkk, 2018).

Plankton juga merupakan rantai makanan pertama di dalam ekosistem perairan, yang keanakeragamannya dapat mempengaruhi keberlangsungan hidup biota lain, seperti nekton. Keberadaan plankton dapat menjadi salah satu kegiatan yang menunjang ekowisata, yaitu memancing. Keanekaragaman plankton yang tinggi mempengaruhi jumlah nekton di Danau Rawapening, dimana semakin tinggi keanekaragaman plankton maka jumlah nekton semakin meningkat (Azmi dkk, 2015).

Makrobenthos adalah biota yang digunakan sebagai parameter biologi dalam menentukan kondisi suatu perairan. Berdasarkan pengamatan yang telah dilakukan di Danau Rawapening Kabupaten Semarang terdapat 20 jenis makrobenthos dengan indeks keanekaragaman dan kemerataan masing-masing 1.86 dan 0.62. Jenis makrobenthos yang ditemukan di Danau Rawapening adalah Anentome sp, Brotia hoabinensis, Chrysops discalis, Clea sp, Gabia smithii, Jardinella carnarvonensis, Lethocerus americanus, Lumbricus terestris, Macrobranchium lamarrei, Melanoides turricula, Orthetrum crisis, Parathelpus convexa, Radix rubiginosa, Sermyla requeti, Sermyla venustula, Stellaria solaris, Tarebia granifera, Tatea rufilabris,
Thiara australis, dan Tylomelania palicolarum. Jumlah individu yang paling banyak ditemukan yaitu Tarebia granifera (3680 individu/ $\mathrm{m}^{2}$ ).

Tingkat keanekaragaman makrobenthos danau rawapening tergolong sedang dengan indeks kemerataan yang tinggi. Hal tersebut menunjukkan daya tahan ekosistem terhadap tekanan ekologis dan kestabilan dominasi perairan yang cukup. Hal ini sesuai dengan penelitian terdahulu yang penyatakan bahwa keanekaragaman makrobenthos yang tinggi menunjukkan daya tahan ekosistem terhadap tekanan ekologis yang tinggi (Hazarika, 2013) sedangkan keanekaragaman yang rendah mengindikasikan terjadinya ketidakstabilan karena ada jenis yang mendominasi perairan di dalam ekosistem (Pawhestri dkk, 2015). Kondisi tersebut juga menyebabkan daya tahan ekosistem terhadap tekanan lingkungan juga rendah (Tambunan dkk , 2005). Tingkat kemerataan makrobenthos juga tergolong tinggi, menunjukkan tidak adanya dominasi spesies makrobentos dan peluang hidup yang merata (Pawhestri dkk, 2015).

Daya tahan ekosistem perairan yang tinggi terhadap tekanan lingkungan dapat mendukung berbagai kegiatan yang berhubungan dengan ekowisata, seperti memancing (Decenly dkk, 2014). Sisi lain, penelitian terahulu menyatakan bahwa makrobenthos merupakan salah satu sumber makanan untuk berbagai burung, seperti famili ardaidae. Hal ini menunjukkan bahwa makrobenthos mampi bertindak sebagai faktor pendukung dalam menunjang kegiatan ekowisata yang berkaitan dengan burung (Tiga dkk, 2019). Penjelasan terkait kegiatan ekowisata menyangkut burung akan dibahas selanjutnya.

Nekton merupakan organisme vertebrata yang termasuk dalam Filum Chordata dimana mampu hidup dan bergerak bebas di suatu perairan serta mempunyai karakteristik khas berupa insang dan sirip. Nekton mempunyai karakter yang berbedabeda dan ditemukan hampir di seluruh tipe perairan di dunia. Berdasarkan pengamatan yang telah dilakukan di Danau Rawapening Kabupaten Semarang terdapat 13 jenis nekton dengan indeks keanekaragaman dan kemerataan dan dominasi masing-masing 2.38 dan 0.93 . Jenis nekton yang ditemukan di Danau Rawapening Kabupaten Semarang antara lain Anabas testudineus, Aplocheilus sp, Channa striata, Clarias batrachus, Dermogenys pusilla, Hypostomus plecostomus, Osteochilus hesselti, Oreochromis mossambicus, Oreochromis niloticus, Puntius sp, Rasbora lateristriata, Trichogaster trichopterus, dan Yongeichthys sp. Jumlah individu yang paling banyak ditemukan yaitu Oreochromis niloticus (12 individu $/ \mathrm{m}^{3}$ ).

Penelitian terdahulu menyatakan bahwa banyaknya spesies nekton di suatu perairan dapat merepresentasikan kompleksitas komunitas nekton di perairan tersebut (Adrim dan Fahmi, 2010). 
Tingkat keanekaragaman nekton di danau rawapening tergolong sedang dengan indeks kemerataan yang tinggi. Tingkat keanekaragaman nekton yang sedang menunjukkan tingkat kompleksitas komunitas nekton yang cukup dan tidak adanya spesies yang mendominasi di perairan tersebut. Hal ini sesuai dengan penelitian terdahulu yang menyatakan bahwa tinggi rendahnya tingkat keanekaragaman menunjukkan tingkat kestabilan dominasi spesies di suatu ekosistem (Pawhestri dkk, 2015). Kondisi tersebut juga menyebabkan daya tahan ekosistem terhadap tekanan lingkungan yang rendah (Tambunan dkk , 2005). Hal ini juga didukung dengan hasil penelitian yang menunjukkan tingkat kemerataan nekton juga tergolong tinggi, menunjukkan tidak adanya dominasi spesies nekton dan peluang hidup yang merata (Azmi dkk, 2015).

Burung merupakan satwa liar yang mudah dijumpai di lingkungan bervegetasi dimana habitatnya mencakup beragam tipe ekosistem. Luasnya penyebaran menjadikan burung sebagai salah satu sumber kekayaan hayati potensial. Keberadaan burung sangat terpengaruh akibat adanya alih guna lahan hutan, padahal perannya penting dalam ekosistem antara lain sebagai penyerbuk, pemencar biji, pengendali hama. (Ayat, 2011).

Berdasarkan data sekunder hasil penelitian yang dilakukan oleh Khalida (2015) yang sudah dimodifikasi menunjukkan bahwa terdapat 34 jenis burung di kawasan Danau Rawa Pening. Kawasan danau tersebut didominasi oleh spesies Bubulcus ibis (222 individu), Tringa glareola (134 individu), Lonchura leucogastroides (124 individu), Ardeola bacchus (85 individu) dan Cisticola juncidis (56 individu).

Bubulcus ibis, Tringa glareola, dan Lonchura leucogastroides merupakan spesies dengan jumlah individu yang paling banyak ditemukan. Area persawahan yang terdapat di sekitar Danau Rawa Pening memancing berbagai jenis burung tersebut untuk mendatangi wilayah tersebut. Famili Ardeideae dan juga Jenis Tringa yang mencari makan berupa cacing, remis dan gastropoda yang berada di tanah berlumpur. Jumilawaty dkk (2011) menyatakan bahwa kuntul mencari makan berkelompok dengan sesama kuntul maupun dengan burung cangak dan bluwok tanpa adanya persaingan. Ikan adalah makanan utaman burung kuntul, disamping kelompok crustacea, amfibi, dan mamalia kecil (Rukmi, 2002). Studi terdahulu juga menyebutkan bahwa Lonchura sangat menyukai daerah persawahan karena sumber pakan burung ini adalah biji-bijian (menurut MacKinnon dkk, 2010)

Berdasarkan hasil penelitian yang dilakukan oleh Khalida (2015), diperoleh indeks keanekaragaman dan kemerataan burung di danau rawa pening sebesar 2.14 dan 0.42. Hal ini menunjukkan tingkat keanekaragaman dan kemerataan burung di Danau Rawapening yang tergolong sedang, menujukkan tingkat kompleksitas komunitas burung yang cukup dan dominasi spesies yang sedang. Hal tersebut dapat menjadi bukti bahwa kegiatan ekowisata yang berkaitan dengan burung masih dapat dilakukan. Penelitian terdahulu menyatakan bahwa keanekaragaman burung yang melimpah di suatu kawasan danau dapat dikaitkan dengan kegiatan jika dikaitkan dengan kegiatan ekowisata, seperti bird watching (Mochtar, 2014). Suara burung yang khas dan warna bulu dari berbagai jenis burung yang dijumpai di kawasan danau dapat menjadi daya tarik tersendiri (Jamilawaty dkk, 2011).

Tumbuhan air di suatu kawasan perairan mempunyai beberapa manfaat, yaitu dapat menjernihkan air, menjaga kebersihan danau dan memberikan nilai estetika bagi keindahan danau. Namun, jika jumlahnya terlalu banyak sehingga tidak dapat dikendalikan (blooming) maka dapat mengganggu ekosistem danau dan menjadi gulma. Gulma adalah tumbuhan yang tumbuh di area yang tidak diinginkan karena dapat mengganggu organisme lain yang berada di area tersebut. Adaptasi yang sangat baik terhadap lingkungan dan reproduksinya yang sangat cepat merupakan karakteristik gulma.

Berdasarkan pengamatan yang telah dilakukan di Danau Rawapening terdapat beberapa tumbuhan air antara lain Eichhornia crassipes, Fimbristylis globulosa, Hydrilla verticillata, Lemna perpusilla, Limnobium spongia, Monochoria hastate, Nymphaea pubescens, Pistia stratiotis, Sacciolepis interupta, Salvinia cucculata, Salvinia molesta, Scirpus grossus, dan Typha latifolia. Tumbuhan yang paling banyak terdapat di Danau Rawapening adalah Eichhornia crassipes (eceng gondok).

Eichhornia crassipes merupakan tanaman yang hidup mengapung di air hingga berakar dalam tanah. Eichhornia crassipes dapat dimanfaatkan sebagai bahan pupuk kompos karena kandungan mineral yang tinggi dan mampu menyerap hara di dalam perairan sehingga dapat meningkatkan kualitas tanah. Sisi lain, tanaman tersebut juga dapat dimanfaatkan sebagai bahan kerajinan, dan pakan ternak karena mengandung senyawa organik antara protein, selulosa dan eter. Berbagai potensi pemanfaatan tersebut dapat faktor yang mampu meningkatkan nilai ekowisata, menyangkut kegiatan perekonomian dan daya tarik wisata yang dapat dimanfaatkan oleh masyarakat (Tanaya dan Rudiarto, 2014).

Danau Rawapening merupakan ekosistem danau yang dapat mengalami perubahan tingkat kedalaman air berdasarkan musim, sehingga mempengaruhi kondisi kualitas air dan berdampak pada penentuan struktur komunitas organisme yang hidup di ekosistem danau. Perubahan kualitas perairan mengakibatkan organisme bermigrasi ke 
luar ekosistem karena tidak mampu beradaptasi terhadap kondisi lingkungan. Selain itu, perubahan kedalaman air juga merupakan salah satu faktor yang menyebabkan organisme melakukan migrasi baik untuk bereproduksi maupun mencari makanan. Perbedaan komposisi jenis organisme antar perairan disebabkan oleh perbedaan karakteristik kualitas air dan struktur habitat (Sulistiyarto dkk, 2007).

Perubahan suhu ekosistem perairan dapat berdampak terhadap kondisi fisika, kimia, dan biologi badan air. Hasil penelitian menunjukkan perairan Danau Rawapening tidak berbau. Danau rawapening juga mempunyai warna perairan hijau kecoklatan dan agak jernih, yang diakibatkan oleh kandungan bahan organik dan anorganik seperti plankton, humus, ion-ion logam dan berbagai bahan lain. Penelitian terdahulu melaporkan bahwa warna kecoklatan disebabkan karena adanya bahan-bahan organik, misalnya lignin, tannin dan asam humus dari dekomposisi tumbuhan (Effendi, 2003). Hal tersebut menunjukkan bahwa perairan Danau Rawapening masih dapat mendukung untuk kegiatan ekowisata, seperti berperahu dan memancing. Danau Rawapening yang tidak berbau juga menunjukkan ekosistem biotik perairan yang baik dan dapat dimanfaatkan untuk berbagai kegiatan ekowisata perairan, seperti memancing. Hal ini didukung dengan kandungan berbagai bahan organik dan

Hasil penelitian juga menunjukkan bahwa derajat keasaman $(\mathrm{pH})$ perairan Danau Rawapening berada pada kirasaran 6.97. Hal tersebut menunjukkan perairan Danau Rawapening mempunyai derajat keasaman yang netral. Penelitian terdahulu menyatakan bahwa derajat keasaman air merepresentasikan sifat kimia, menentukan kualitas air dan memepengaruhi proses biokimiawi perairan. Biota akuatik sensitif dapat tumbuh dengan baik pada rentang nilai $\mathrm{pH}$ sekitar 6,8-7,2. Hal tersebut juga menunjukkan bahwa perairan danau memenuhi baku mutu air berdasarkan PP No.82 tahun 2001 kelas II yaitu baku mutu air untuk sarana rekreasi dan perikanan yang berada diantara 6-9. Derajat keasaman yang netral pada Danau Rawapening dapat menjadi faktor pendukung kegiatan ekowisata perairan karena merupakan indikator yang baik untuk kehidupan biota akuatik.

Kadar oksigen terlarut (DO) menunjukkan jumlah oksigen yang terlarut dalam air (mg/L). Kadar oksigen terlarut dapat sangat bervariasi dan bergantung pada salinitas, turbulensi air, suhu dan tekanan atmosfer. Suhu dan ketinggian (altitude) yang semakin tinggi dan tekanan atmosfer yang semakin rendah menyebabkan semakin kecilnya kadar oksigen terlarut (Effendi, 2003). Oksigen terlarut hasil pengukuran di Danau Rawapening adalah berkisar 3,9-6,7 mg/l. Kadar oksigen terlarut di perairan tersebut dapat dikatakan memenuhi baku mutu air PP No.82 tahun 2001 kelas II. Kadar oksigen terlarut disarankan tidak kurang dari $3 \mathrm{mg} / \mathrm{l}$ untuk kehidupan biota perairan pada umumnya (Effendi, 2003). Keberadaan oksigen danau tersebut lebih banyak dihasilkan oleh fotosintesis tumbuhan air, dilihat dari kondisi fisik yang mengalami pendangkalan dan banyak ditumbuhi tumbuhan air pada zona litoral. Oksigen terlarut di perairan umum berasal dari hasil proses fotosintesis tumbuhan air yang ada atau difusi dari udara (asanya riak air menghasilkan aerasi). Kadar oksigen terlarut yang baik di perairan Danau Rawapening menunjukkan bahwa perairan tersebut mampu mendukung kondisi kehidupan biota perairan sehingga dapat meningkatkan potensi kegiatan ekowisata perairan.

Berdasarkan hasil pengumpulan data primer dan sekunder, penilaian potensi daerah tujuan wisata Bukit Cinta Danau Rawapening dilakukan berdasarkan pedoman Analisis Daerah Operasi Obyek Dan Daya Tarik Wisata Alam (ADO-ODTWA) dari Direktorat Jenderal Perlindungan Hutan dan Konservasi Alam tahun 2013. Sebanyak 15 kriteria digunakan untuk mengetahui kondisi daerah tujuan wisata dengan menentukan skala prioritas pengembangan kawasan wisata. Hasil penilaian potensi daerah tujuan wisata Bukit Cinta Danau Rawapening disajikan pada Tabel 2.

Tabel 2. Kriteria Potensi Objek Wisata di Bukit Cinta Danau Rawapening berdasarkan ADO-ODTWA

\begin{tabular}{clcc}
\hline No. & \multicolumn{1}{c}{ Kriteria Penilaian } & Nilai & Klasifikasi \\
\hline 1. & Daya tarik obyek wisata darat & 1170 & Tinggi \\
2. & Potensi pasar & 900 & Tinggi \\
3. & Kadar hubungan/ aksesibilitas & 525 & Tinggi \\
4. & Kondisi sekitar kawasan & 875 & Sedang \\
5. & Pengelolaan dan pelayanan & 280 & Tinggi \\
6. & Iklim & 320 & Sedang \\
7. & Akomodasi & 60 & Sedang \\
8. & Sarana dan prasarana penunjang & 180 & Tinggi \\
9. & Ketersediaan air bersih & 840 & Tinggi \\
10. & Hubungan dengan obyek wisata di sekitarnya & 140 & Tinggi \\
11. & Keamanan & 500 & Tinggi \\
12. & Daya dukung kawasan & 255 & Sedang \\
13. & Pengaturan pengunjung & 30 & Rendah \\
14. & Pemasaran & 100 & Tinggi \\
15. & Pangsa pasar & 120 & Rendah \\
\end{tabular}


Hasil identifikasi potensi berdasarkan ADOODTWA menunjukkan bahwa objek wisata Bukit Cinta Danau Rawapening termasuk dalam klasifikasi tinggi dengan nilai 6310. Hal ini mengindikasikan bahwa objek wisata tersebut berpotensi untuk dikembangkan menjadi destinasi ekowisata. Sisi lain, beberapa identifikasi potensi memiliki penilaian yang rendah, seperti pengaturan pengunjung dan harga pasar, sehingga diperlukan fokus perbaikan dalam pengembangan sebuah destinasi ekowisata (Gunn, 1997).

\section{Kesimpulan}

Tumbuhan air yang mendominasi adalah Eichhornia crassipes. Struktur komunitas fitoplankton menunjukkan kelimpahan yang didominasi oleh Melosira sp. dimana indeks keanekaragamannya tergolong dalam kelompok sedang dengan distribusi yang merata. Koefisien saprobic menujukkan golongan Oligosaprobik sampai $\beta / \alpha$-Mesosaprobik yang menunjukkan tingkatan tercemar sangat ringan hingga tercemar ringan. Faktor fisika kimia perairan tergolong baik bagikehidupan organisme perairan. Hal ini menunjukkan Bukit Cinta Dana Rawapening berada dalam kondisi yang stabil dan berpotensi dikembangkan sebagai destinasi ekowisata yang baik. Hal tersebut juga didukung oleh hasil penilaian identifikasi potensi berdasarkan ADO-ODTWA yang tinggi.

\section{DAFTAR PUSTAKA}

Adrim, M., dan Fahmi. 2010. Panduan Penelitian untuk Ikan Laut. Pusat Penelitian Oseanografi-LIPI. Jakarta.

APHA (American Public Health Association). 2005. Standart Methods for Examination of Water and Wastewater. Twentieth edition. APHA- AWWA-WEF, Washington, D.C., p.10-2-10-18.

Aryanto, T., H, Purnaweni., dan T. R. Soeprobowati. 2016. Daya Dukung Jalur Pendakian Bukit Raya di Taman Nasional Bukit Baka Raya Kalimantan Barat. Jurnal Ilmu Lingkungan. Vol.14(2):72-76.

Ayat, A. 2011. Burung-burung Agroforest di Sumatera. World Agroforesty Centre. Bogor.

Azmi, N., Yunasfi, dan A. Muhtadi. 2015. Struktur Komunitas Nekton di Danau Pondok Lapan Desa Naman Jahe Kecamatan Salapian Kabupaten Langkat. Jurnal Manajemen Sumberdaya Perairan. Vol.4(9):43-56.

Champalbert, G., M. Pagano, P. Sene, and D. Corbin. 2007. Relationship between mesoand macro-zooplankton communities and hydrology in the Senegal River Estuary. Estuarine, Costal and Shelf Science. Vol.74:381-394.

Damanik, J., dan Helmut. F. W. 2007. Perencaan Ekowisata dari Teorike Aplikasi. Penerbit ANDI. Pusat Studi Pariwisata (PUSPAR) UGM. Yogyakarta.

Decenly., T. R. Soeprobowati., dan F. Muhammad. 2014. Potensi Ekowisata Danau di Kawasan Kamipang
Kalimantan Tengah. Jurnal Biosaintifika Vol.6(2):8797.

Departemen Kehutanan Ditjen PHKA. 2003. Pedoman Analisis Daerah Operasi Obyek dan Daya Tarik Wisata Wisata Alam (ADO-OTDWA). Bogor. Direktorat Wisata Alam dan Pemanfaatan Jasa Lingkungan.

Dresscher, T. G. N., and H. Van Der Mark. 1974. A Simplified Method for The Assessment of Quality of Fresh and Slightly Brakish Water. Journal Hydrobiologia, Vol.48(3):199-201.

Effendi, H. 2003. Telaah Kualitas Air bagi Pengelolaan Sumber Daya Lingkungan Perairan. Kanisius. Yogyakarta.

Gunn, C. A. 1997. Vacationscape Developing Tourist Areas. Taylor \& Francis. USA.

Hazarika, L. P. 2013. Diversity indices of macro invertebrates in the Satajan Wetland of Lakhimpur District, Assam. Journal Annals of Biological Research. Vol.4(8):68-72.

Jumilawaty, E., A. Mardiastuti., L. Budiprasetyo., dan Y. A. Mulyani. 2011. Keanekaragaman Burung Air di Bagan Percut, Deli Serdang Sumatera Utara. Media Konservasi. Vol.16(3):108-113.

Khalida, N. 2015. Struktur Komunitas Burung Diurnal di Danau Rawa Pening, Kabupaten Semarang, Jawa Tengah. Skripsi. Fakultas Sains dan Matematika Universitas Diponegoro. Semarang.

Lathifah, N., J. W. Hidayat., dan F. Muhammad. 2017. Struktur Komunitas Fitoplankton sebagai Dasar Pengelolaan Kualitas Pantai Mangrove di Tapak Tugurejo Semarang. Jurnal Bioma: Berkala Ilmiah Biologi. Vol.19(2):164-169.

MacKinnon, J., K. Phillips., B. Van Balen. 2010. Burungburung di Sumatera, jawa, Bali, Kalimantan. Puslitbang Biologi-LIPI/ Birdlife Indonesia Programme.

Machnaughton, J.C, S. Harvey-Lavoie, C. Senay, G. Lanthier, G. Bourque, P. Legendre, and D. Boisclair. 2015. A Comparison Of Electrofishing and Visual Surveying Methods For Estimating Fishing Community Structure in Temperate Rivers. River Res. Applic. Vol.31:1040-1051.

Magurran, A. E. 1988. Ecological Diversity and Its Measurement. Pricenton University Press. USA.

Mochtar, T. 2004. Studi Optimalisasi Potensi di Kawasan Rawapening. Balitbang Provinsi JawaTengah bekerjasama dengan Fakultas Teknik UNDIP.

Odum, E. P. 1996. Dasar-Dasar Ekologi Edisi Ketiga. Gajah Mada Universitas Press. Yogyakarta.

Pawhestri. S. W., J. W. Hidayat., dan S. P. Putro. 2015. Assessment of Water Quality Using Macrobenthos as Bioindicator and Its Application on AbundanceBiomass Comparison (ABC) Curves. Internasional Journal of Science and Engineering (IJSE). Vol.8(2).

Piranti, A. S., D. R. U. S. Rahayu., dan G. Waluyo. 2018. Nutrient Limiting Factor for Enabling Algae Growth of Rawapening Lake, Indonesia. Journal Biosaintifika. Vol.10(1):101-108. 
Rukmi, D. S. 2002. Perilaku dan Kompetisi Interspesifik Kuntul Beasar dan Cangak Merah di Suaka Margasatwa Pulau Rambut Jakarta. Pasca Sarjana IPB. Bogor.

Sugiyono. 2011. Metode Penelitian Kuantitatif dan Kualitatif dan R \& D. CV Alfabeta. Bandung.

Sulistiyarto, B., D. Soedharma., M. F. Raharjo., dan Sumardjo. 2007. Pengaruh Musim terhadap Komposisi Jenis dan Kelimpahan Ikan di Rawa Lebak, Sungai Ruangan, Palangkaraya, Kalimantan Tengah. Jurnal Biodiversitas. Vol.8 (4) Hal.270-273.

Tambunan, R., R. H. Harahap dan Z. Lubis. 2005. Pengeloan Hutan Mangrove di Kabupaten Asahan (Studi Kasus Partisipasi Masyarakat dalam Pengeloaan Hutan
Mangrove di Kecamatan Lima Puluh Kabupaten Asahan). Jurnal Studi Pembangunan. Vol.1(1).

Tanaya, D. R., dan I. Rudiarto. 2014. Potensi Pengembangan Ekowisata Berbasis Masyarakat di Kawasan Rawa Pening, Kabupaten Semarang. Jurnal Teknik PWK UNDIP. Vol.3(1):71-81.

Taqwa, R. N. 2014. Studi Hubungan Substrat Dasar dan Kandungan Bahan Organik dalam Sedimen dengan Kelimpahan Hewan Makrobenthos di Muara Sungai Sayung Kabupaten Demak. Jurnal Management of Aquatic Resources Vol.3 No.1 Hal.125-133.

Tiga, M. R. M., E. I. K. Putri., dan M. Ekayani. 2019. Analisis Potensi Kawasan Laiwangi Wanggameti di Taman Nasional Matalawa untuk Arahan Pengembangan Ekowisata. Jurnal Ilmu Lingkungan. Vol.17(1):32-41 